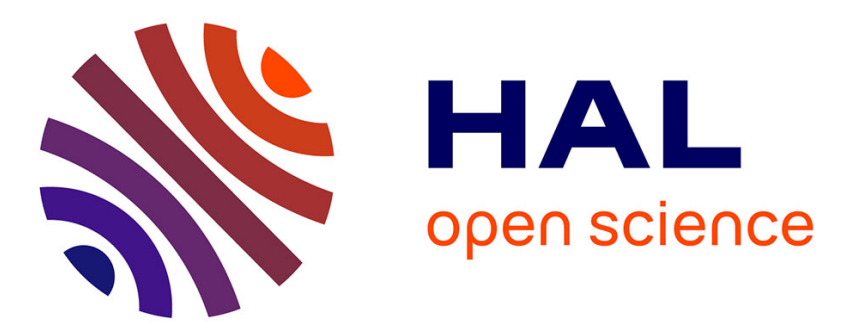

\title{
An individual-based model of hepatitis a transmission
}

\author{
Marco Ajelli, Stefano Merler
}

\section{To cite this version:}

Marco Ajelli, Stefano Merler. An individual-based model of hepatitis a transmission. Journal of

Theoretical Biology, 2009, 259 (3), pp.478. 10.1016/j.jtbi.2009.03.038 . hal-00554600

\section{HAL Id: hal-00554600 \\ https://hal.science/hal-00554600}

Submitted on 11 Jan 2011

HAL is a multi-disciplinary open access archive for the deposit and dissemination of scientific research documents, whether they are published or not. The documents may come from teaching and research institutions in France or abroad, or from public or private research centers.
L'archive ouverte pluridisciplinaire HAL, est destinée au dépôt et à la diffusion de documents scientifiques de niveau recherche, publiés ou non, émanant des établissements d'enseignement et de recherche français ou étrangers, des laboratoires publics ou privés. 


\section{Author's Accepted Manuscript}

An individual-based model of hepatitis a transmission

Marco Ajelli, Stefano Merler

PII:

S0022-5193(09)00146-5

DOI: doi:10.1016/j.jtbi.2009.03.038

Reference: YJTBI 5522

To appear in:

Journal of Theoretical Biology

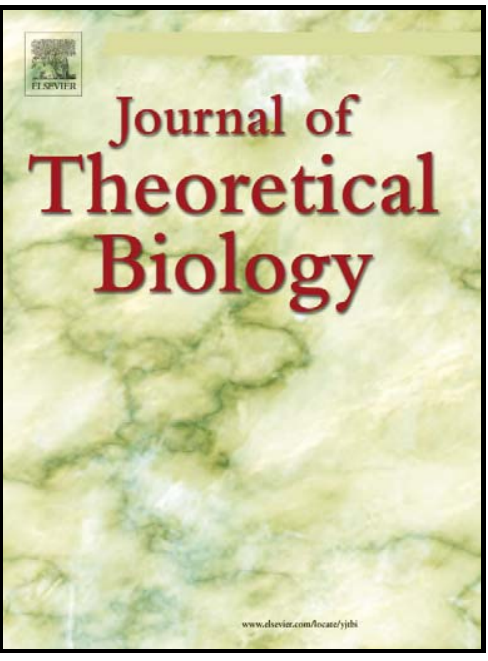

www.elsevier.com/locate/yjtbi

Received date: $\quad 23$ October 2008

Revised date: $\quad 31$ March 2009

Accepted date: $\quad 31$ March 2009

Cite this article as: Marco Ajelli and Stefano Merler, An individual-based model of hepatitis a transmission, Journal of Theoretical Biology (2009), doi:10.1016/j.jtbi.2009.03.038

This is a PDF file of an unedited manuscript that has been accepted for publication. As a service to our customers we are providing this early version of the manuscript. The manuscript will undergo copyediting, typesetting, and review of the resulting galley proof before it is published in its final citable form. Please note that during the production process errors may be discovered which could affect the content, and all legal disclaimers that apply to the journal pertain. 


\title{
An individual-based model of hepatitis A
}

\section{transmission}

\author{
Marco Ajelli ${ }^{\mathrm{a}, \mathrm{b}, *}$ Stefano Merler ${ }^{\mathrm{a}}$

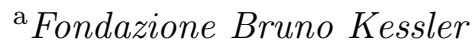 \\ ${ }^{\mathrm{b}}$ Information Engineering and Computer Science Department, University of \\ Trento
}

\begin{abstract}
Viral hepatitis A, as other endemic diseases, represents a public health priority worldwide. To study long-time scale human pathogens through individual-based simulations requires the development of a dynamic network of contacts. In this work, we introduce an individual-based model accounting for the birth and death of the individuals, the generation of new households, and the educational career of the individuals, in order to investigate viral hepatitis A dynamics in the most affected Italian areas. Intervention options such as targeted vaccination, social distancing measures (e.g. closure of day care centers and kindergartens) and improvements in standards of living and hygiene are evaluated. Results show that a very low vaccination coverage is sufficient to control hepatitis A in Italy, while its elimination is not possible since new cases are continuously imported from high endemicity areas outside the country. Finally, the considered social distancing measures can be counterproductive since the fraction of recovered individuals does not decline while the age at infection increases, thus augmenting the probability of developing acute symptoms.
\end{abstract}


Key words: Mathematical modeling, computer simulations, disease transmission, endemic diseases

\section{Introduction}

Hepatitis A virus (HAV) is the cause of viral hepatitis A infection, which results in an acute form of hepatitis. Patients recover completely and develop full immunity against future HAV infections (Stapleton and Lemon, 1994). Nevertheless, viral hepatitis A represents an important public health issue, imposing a remarkable economic burden worldwide (Berge et al., 2000; Das, 2003) and in Italy as well (Lucioni et al., 1998).

HAV is transmitted via the fecal-oral route by person-to-person contact (direct transmission) or by ingestion of contaminated food or water (indirect transmission). Indirect transmission represents the most important source of infection in countries with high living standards (Fiore, 2004; Lopalco et al., 1997). Specifically, raw mussels and shellfish consumption represents the main source of infection in Italy (Mele et al., 2006), especially in the most affected regions: Puglia and Campania (Chironna et al., 2002, 2003; Salamina and D'Argenio, 1998). Another significant source of infection is represented by travels to high endemicity areas (Mele et al., 2006), where both direct and indirect transmission can occur.

\footnotetext{
* Fondazione Bruno Kessler, via Sommarive 18, I-38100 Trento, Italy. Tel: +39 0461314523 , Fax: +390461314591.

Email addresses: ajelli@fbk.eu (Marco Ajelli), merler@fbk.eu (Stefano Merler).
} 
Nowadays, even in the absence of vaccination, hepatitis $\mathrm{A}$ is in a decaying phase, mainly determined by improved hygienic conditions derived from economic development and higher standards of living (Jacobsen and Koopman, 2004, 2005). Although this is true also for Italy as a whole, as documented by both notification (Mele et al., 2006; ISTAT, 1980-2006) and serological data (D'Amelio et al., 2005), Southern Italy shows a different pattern. HAV infections are still common in Puglia and Campania, two regions in Southern Italy, where a very large outbreak was observed in 1996-1997 (Lucioni et al., 1998), despite the improvement of socio-economic conditions.

Thanks to a new generation of mathematical modeling tools, the effectiveness of both pharmaceutical (e.g., treatment or prophylaxis on a contact tracing basis) and non-pharmaceutical (e.g., social distancing) individually targeted intervention measures can be thoroughly investigated. Recently, highly detailed individual-based models have been developed for evaluating the effectiveness of control measures for diseases such as pandemic influenza (Germann et al., 2006; Ferguson et al., 2005, 2006; Longini et al., 2005, 2004; Ciofi degli Atti et al., 2008) or fighting back a bioterroristic attack (e.g., by employing smallpox virus) (Eubank et al., 2004; Longini et al., 2006; Riley and Ferguson, 2006; Halloran et al., 2002). As highlighted by Riley (Riley, 2007), the need arises "to develop a simple model of household demographics, so that these largescale models can be extended to the investigation of long-time scale human pathogens". In fact, endemic diseases such as tuberculosis, measles, malaria, hepatitis and HIV represent important public health issues worldwide (Murray and Lopez, 1997).

In this work we introduce an individual-based model for investigating the dynamics of viral hepatitis $\mathrm{A}$ in the most affected Italian areas, and for evalu- 
ating the effectiveness of intervention options. The model is based on the real sociodemographic composition of the population and it takes into account the vital dynamics of the population and the changes in the network of contacts (e.g., due to the birth and death of individuals, the generation of new households, the educational career of individuals).

Since hepatitis $\mathrm{A}$ is a vaccine-preventable disease, we have evaluated the effectiveness of different vaccination programmes. Moreover, we have analyzed the effects of improvements in standards of living and hygiene and of social distancing measures, such as isolation of symptomatic cases and closure of day care centers and kindergartens.

Results show that a very low vaccination coverage is sufficient to control hepatitis $\mathrm{A}$ in Italy. The above described social distancing measures do not have any positive effect in decreasing the seroprevalence. Moreover, an undesired effect of the considered social distancing measures is to decrease the fraction of children and adolescents contracting the infection while increasing that of adults and elderly people. Improvements in hygienic conditions can remarkably decrease the seroprevalence. Finally, the elimination of hepatitis A appears unfeasible since new cases are continuously imported from high endemicity areas outside the country.

\section{Methods}

We have developed an individual-based model with dynamic network of contacts, parameterized by employing sociodemographic and epidemiological data and accounting for millions of individuals. The main ingredients of the model 
are: (i) the sociodemographic model, simulating the temporal evolution of the population; (ii) the transmission model, simulating the temporal evolution of the epidemic.

\subsection{Sociodemographic model}

\subsubsection{Initialization of the network of contacts}

The contact network among individuals is adapted from the one introduced in (Ajelli and Merler, 2008). Basically, each individual is explicitly represented in the model and the network of contacts is generated by co-locating individuals in households, schools and workplaces.

The populations of Campania (5,701,931 inhabitants) and Puglia (4,020,707 inhabitants) are modeled. Individuals are hierarchically grouped within the region of residence by municipalities and provinces, according to the administrative borders of the study area and to the number of individuals by municipality.

Census data on population, household type and size (ISTAT, 2001b) and data on age structure (ISTAT, 2007) are jointly used with survey data (ISTAT, 2003) to randomly assign age and co-locate individuals in households. Data on the age structure are specific for the two regions, while survey data refer to an analysis conducted at national level. Nine different household types are considered in the model. Comparison between real and simulated age structure and between real and simulated household size frequencies are reported in Figure 1. 
Demographic, school (MIUR, 2005a,b) and industry census data (ISTAT, 2001a) are used for generating schools and workplaces, and for randomly assigning an employment category (student, worker, unemployed) to each individual on the basis of age and employment rates by age (which also include rates of school attendance). Six school types, from day care to university, are considered in the model. School employees (e.g. teachers) are located in schools and not in generic workplaces.

Commuting destinations for both workers and students are randomly assigned by employing a gravity model (Viboud et al., 2006), integrated with specific data (ISTAT, 2001b).

All the details on the initialization of the sociodemographic model are given in the Supplementary Materials.

\subsubsection{Dynamic network of contacts}

The vital dynamics of the population has to be considered for modeling endemic diseases. This implies that the network of contacts among individuals has to be kept updated. In particular, in the proposed model, individuals come to life, grow, can generate new households, can procreate and die; moreover, they can attend school (following the educational career), have an employment and retire.

The population is assumed to be closed, i.e. without immigration and emigration, and with a constant number of individuals, i.e. the number of deaths corresponds to the number of newborns. Despite Italy has one of the lowest fertility rates worldwide, it has experienced a large immigration since the 
1990s (Iannelli and Manfredi, 2007), which has contributed to slightly increase the Italian population. Campania and Puglia followed the completely opposite pattern. The demographic balance is positive, with an excess of births over death, but the two regions have experienced a large emigration. As a consequence, in the last 5 years Campania and Puglia populations have been constant in size: the variations (both positive and negative) have been less than $0.7 \%$ per year (data shown in Table 7 of the Supporting Materials). Therefore, assuming a constant number of individuals can be considered as a reliable modeling choice.

Births replace dead individuals, which are randomly selected on the basis of the mortality rates by age, specific for the two considered regions (ISTAT, 1974-2004). Each newborn is located in an existing household, chosen among those of suitable size and members age. Finally, it is determined whether the newborn is enrolled in a day care center or not.

Individuals who have not already generated their own family and are at least 18 years old can generate a new household group, possibly a single member household, on the basis of the probability of getting married by age (ISTAT, 2008).

Every time the population is updated the age of each individuals is increased and an employment category (possibly, "unemployed") is associated to each individual on the basis of the employment rates by age. If this category is the same that she/he had before the update she/he keeps her/his place, otherwise a new school/workplace is randomly chosen among the existing ones. In the latter case, the commuting destination is determined by employing the same gravity model employed for the initialization of the network of contacts. As 
regards the students, the school type (day care center, kindergarten, primary, middle, high school, university) is deterministically assigned on the basis of the age of the individual (see Table 6 in the Supplementary Material). Since the age of the individuals is kept updated, the previously described procedure allows students to follow the educational career.

Figure 2 shows the sociodemographic projections for the years 2012, 2017 and 2020 in terms of age structure, frequencies of households size and employment category. These projections show a progressive population aging (Figure 2a and $2 \mathrm{~b}$ ) and the consequent decrease in the number of students and workers and the increase in the number of retired individuals (Figure 2e and 2f). These demographic projections comply with the Italian situation. In fact, nowadays, Italian population is undergoing a phase of progressive aging. For validating these demographic projections, we initialized the population of both Campania and Puglia with their age-structure in the 2002 and compared them with the age-structure simulated by the model using these data as input. Then we ran the simulations and compared the age-structure in the 2007 with the one predicted by the model. As shown in Figure 8 in the Supplementary Materials, the predicted age-structures for both Puglia and Campania are in good agreement with the real data.

Further details on the evolution of the network are given in the Supplementary Materials. 


\subsection{Epidemic transmission model}

The epidemic transmission model is adapted from the one proposed in (Ajelli et al., 2008), which is specific for describing the hepatitis A transmission in Italy. The model accounts for the three main sources of HAV infection in the region: person-to-person transmission, ingestion of infected food and travels to high endemicity areas.

For each susceptible individual $i$, the probability of being infected at time $\tau$ is given by

$$
p_{i}(\tau)=1-e^{-\lambda_{i}(\tau) \Delta t}
$$

where $\lambda_{i}(\tau)$ is the force of infection for the susceptible individual $i$ at time $\tau$, and $\Delta t$ is the time step of the simulation (1 week). $\lambda_{i}(\tau)$ is the sum of the risk factors due to the three considered sources of infection: $\lambda_{i}(\tau)=$ $\lambda_{i}^{D}(\tau)+\lambda_{i}^{S}(\tau)+\lambda_{i}^{T}(\tau)$, where $\lambda_{i}^{D}(\tau)$ represents the direct transmission com-

ponent, $\lambda_{i}^{S}(\tau)$ represents the indirect transmission component and $\lambda_{i}^{T}(\tau)$ the component associated to travels to high endemicity areas.

\subsubsection{Direct transmission}

Direct transmission accounts for person-to-person contacts. Since individualbased models allow the explicit representation of the places where transmission can occur, this transmission component is divided into contacts within households, schools and workplaces.

In particular, for each susceptible individual $i$ the risk factor $\lambda_{i}^{D}(\tau)$ at time $\tau$ is given by: 


$$
\lambda_{i}^{D}(\tau)=\sum_{j \in H_{i}} \frac{I_{j}(\tau) \beta_{h}}{h_{i}-1}+\sum_{j \in P_{i}} \frac{I_{j}(\tau) \beta_{p}^{\vartheta(i)}}{p_{i}-1}
$$

where

- $I_{j}(\tau)$ is equal to 1 if individual $j$ is infectious at time $\tau, 0$ otherwise.

- $H_{i}$ is the set of the indices of the $h_{i}$ individuals living in the same household of $i$ (note that if $h_{i}=1$ the first term in Equation (1) is 0 by definition).

- $\beta_{h}$ is the transmission rate within households.

- $P_{i}$ is the set of the indices of the $p_{i}$ individuals working or studying in the same place of $i$ (if $p_{i}=0$ or $p_{i}=1$ the second term in Equation (1) is 0 by definition).

- $\vartheta(i)$ is the employment category of individual $i$ (i.e., one of the seven types described in the sociodemographic model).

- $\beta_{p}^{\vartheta(i)}$ is the transmission rate within the place of type $\vartheta(i)$.

\subsubsection{Indirect transmission}

Indirect transmission accounts for the infections by ingestion of contaminated seafood. The risk of infection due to this component at time $\tau$ is given by:

$$
\lambda_{i}^{S}(\tau)=\beta_{s}\left(a_{i}\right) U(\tau)
$$

where

- $\beta_{s}\left(a_{i}\right)$ is the transmission rate associated to the ingestion of infected seafood. Since consumption of raw mussels and shellfish varies by age, $\beta_{s}$ is a function of the age of the individual $i$.

- $U(\tau)$ is the quantity of HAV in seafood at time $\tau$, as a consequence of the excretions of infected individuals. 
The variable $U(\tau)$ depends on the number of individuals that were infective prior to time $\tau$, basically because they excrete HAV in the environment during their entire period of infectivity. For simplicity, we decided to model the dynamics of $U(\tau)$ by the following ordinary differential equation:

$$
\frac{d}{d \tau} U(\tau)=\delta\left[\sum_{j=1}^{N} I_{j}(\tau)-U(\tau)\right],
$$

where $\delta$ is the decay rate of HAV in the environment and $\sum_{j=1}^{N} I_{j}(\tau)$ is the number of infectious individuals in the population, which comprises $N$ individuals, at time $\tau$. A discussion on this model of indirect transmission can be found in (Ajelli et al., 2008).

\subsubsection{Travels to high endemicity areas}

Travels to high endemicity areas account for all the infections occurring outside the considered region. This component of the force of infection is modeled as

$$
\lambda_{i}^{T}(\tau)=\beta_{t}\left(a_{i}\right)
$$

which is constant over time and varies by age.

\subsection{Intervention measures}

Since hepatitis A is a vaccine-preventable disease, we will evaluate the effectiveness of different vaccination programmes. Moreover, we will evaluate the effectiveness of social distancing measures. In fact, this is possible mostly thanks to the explicit representation of the individuals and of the places where transmission can occur. Finally, since hepatitis A is undergoing a global decline, due to the worldwide improvements in standards of living and hygiene 
(Jacobsen and Koopman, 2004, 2005), we will draw different scenarios on possible hygienic improvements.

\subsubsection{Vaccination}

For hepatitis A, the target population consists of children and adolescents. We consider newborns and 12 years old adolescents as the target population. Vaccination is modeled by reducing the proportion of susceptible individuals in the target population. This proportion depends on vaccination coverage (i.e., the proportion of target population that is covered in the vaccination campaign) and vaccine effectiveness (i.e., the probability of developing immunity after the administration of a vaccine dose). The latter is kept fixed at $98 \%$ according to (Averhoff et al., 2001). Since vaccination coverage depends on the vaccination programme implemented by public health agencies and on the collaboration of the population, many scenarios are evaluated.

\subsubsection{Social distancing}

The aim of the considered social distancing measures is to interrupt the chains of cases observed in day care centers and kindergartens, which are typical of many childhood diseases (Galil et al., 2002), and viral hepatitis A as well (Chitambar et al., 1996). This is possible thanks to the explicit representation of the individuals and of the places where person-to-person transmission can occur. Specifically, we investigate the effectiveness of the following strategies:

$d 1$ symptomatic individuals are assumed to be isolated for two weeks. In this period they do not transmit the infection neither in their household nor in their school or workplace, if any; 
d2 as d1. Moreover, day care centers and kindergartens attended by symptomatic individuals are closed for 2 weeks;

d3 as d2. Moreover, the policy is extended to day care centers and kindergartens attended by other household members of symptomatic individuals.

The aim of strategy $d 2$ is to limit as much as possible the transmission within day care centers and kindergartens, which are the most important routes of person-to-person HAV transmission (Lerman et al., 1999). Isolation of symptomatic cases is not sufficient to interrupt person-to-person transmission within day care centers and kindergartens, since the probability of being symptomatic in individuals aged 0-6 is very low (about 4\% (Stapleton and Lemon, 1994; Fiore, 2004)). In this respect, the closure of day care centers and kindergartens is required.

The aim of strategy $d 3$ is to limit the transmission within day care centers and kindergartens by suspected infectious individuals, i.e., individuals living in the same household of a symptomatic individual.

Since isolation of symptomatic individuals will hardly occur immediately after the onset of symptoms, we assume a one-week delay between the onset of symptoms and the application of such strategies. We investigate the effectiveness of such strategies when applied to a fraction of the symptomatic individuals or only to notified cases.

Let us note, however, that symptomatic individuals continue to excrete the virus in the environment even if social distancing measures are applied. 


\subsubsection{Modeling hygienic improvements}

In Italy, the main source of contagion is represented by the consumption of infected raw mussels and shellfish (Mele et al., 2006). HAV infection of mussels and shellfish can occur both in the marine environment and in fish market stands where infected water is often employed to wash the shellfish (Shuval, 2003). Thus, we assume that hygienic improvements would be mainly related to the indirect contacts component. Such improvements can be reasonably expected to occur in the considered areas.

We model the improvement of hygienic conditions simply as a reduction of the quantity of infected seafood. In particular, after solving Equation (2), we decrease the value of $U(\tau)$ by a reduction factor accounting for the improved conditions (e.g., better hygiene in the fish markets or better awareness in the choice of fishing areas).

\subsection{Model parametrization}

The basic reproductive number $R_{0}$ is the average number of secondary cases generated by an infectious individual in a completely susceptible population (Anderson and May, 1991). In the absence of any pharmacological interventions, for epidemic outbreaks $R_{0}$ can be estimated from notification data during the initial exponential growth phase of the epidemic (Chowell et al., 2004), while for endemic diseases it can be defined as the inverse of the fraction of susceptible individuals at the endemic equilibrium (Anderson and May, 1991). The latter approach was employed for determining the basic reproductive number of the simulated epidemics. Note that the method can not be applied when 
pharmacological interventions (e.g. vaccination) are implemented.

As regards hepatitis A in Italy, $R_{0}$ was estimated to be 2.9 in Campania and 3.8 in Puglia ${ }^{1}$.

The free parameters of the model are the transmission rates associated to the different sources of infection (i.e. $\beta_{h}, \beta_{p}^{\vartheta}, \beta_{s}(a)$ and $\beta_{t}(a)$ ), while all the other epidemiological parameters (e.g., the latent period and the infectious period) are kept fixed according to the literature (see Table 1). We set the transmission rates in such a way that the fraction of cases generated by each source of infection complies with the risk factors by age as reported in (Mele et al., 2006). In particular, as regards the direct contacts, only transmission within household, day care, kindergarten and primary school is relevant.

Finally, actual hepatitis A notification data (ISTAT, 1980-2006) are used to estimate the reporting rate.

\section{Results}

\subsection{Baseline scenarios}

The risk of infection by age for the three sources of infection estimated by the model agrees well with national survey data as reported in (Mele et al., 2006). A comparison is shown in Figure 3a.

At the endemic equilibrium, the fraction of recovered individuals ${ }^{2}$ estimated

$\overline{1}$ In light of a recent study on the HAV seroprevalence in Italy (Ansaldi et al., 2008), the estimation of $R_{0}$ given by Ajelli et al. (2008) were slightly revised.

2 Individuals who contracted the infection and recovered; vaccinated individuals are 
Table 1

Epidemiological parameters.

\begin{tabular}{|c|c|c|c|}
\hline Parameter & Unit & Value & Reference \\
\hline \multicolumn{4}{|l|}{ Reproductive number } \\
\hline for Campania region & dimensionless & 2.9 & (Ajelli et al., 2008) \\
\hline for Puglia region & dimensionless & 3.8 & (Ajelli et al., 2008) \\
\hline Latent period & weeks & 2 & (CDC, 2007; Stapleton and Lemon, 1994) \\
\hline Infectious period & weeks & 3 & (CDC, 2007; Stapleton and Lemon, 1994) \\
\hline Decay of survival of HAV & weeks $^{-1}$ & 0.0833 & (Ajelli et al., 2008; Abad et al., 1994; Biziagos et al., 1988; Mbithi et al., 1991) \\
\hline \multicolumn{4}{|l|}{ in the environment } \\
\hline \multicolumn{4}{|c|}{ Probability of becoming symptomatic } \\
\hline for individuals aged $0-6$ & percentage & 4 & (Fiore, 2004; Stapleton and Lemon, 1994 \\
\hline for individuals aged $7-16$ & percentage & 16 & (Fiore, 2004; Stapleton and Lemon, 1 \\
\hline for individuals older than 16 & percentage & 80 & (Fiore, 2004; Stapleton and Lemon, 1994) \\
\hline Vaccine efficacy & percentage & 98 & (Averhoff et al., 2001) \\
\hline
\end{tabular}

by the model is $65.8 \%$ in Campania, and $73.8 \%$ in Puglia (see Table 2 and 3). These estimates comply with the seroprevalence data reported in (Ansaldi et al., 2008), where an average value of $67.7 \%$ is reported for Southern Italy. Figure $3 \mathrm{~b}$ shows the fraction of recovered individuals per age cohort, compared with national seroprevalence data (Ansaldi et al., 2008). Age at infection of symptomatic individuals is shown in Figure 3c. Since the age at infection in Puglia is lower than in Campania and the probability of developing symptoms increases with age, the fraction of symptomatic cases in the two regions is not significantly different (38.9\% in Campania and 38.3\% in Puglia).

Hepatitis A cases are seriously under-reported (Armstrong and Bell, 2002). The estimated reporting rate is about 2\% in Campania and $8 \%$ in Puglia. These estimates are quite consistent with those reported by the Centers for Disease Control and Prevention for viral hepatitis A, namely less than $10 \%$ in thus excluded. Basically, it corresponds to the age-adjusted percentage of recovered individuals in the population. 
the US (CDC, 2006). These values are partially justified by the low perceived risk of hepatitis A among the population, especially in Campania where only $39 \%$ of the interviewed people would visit a medical doctor in case of icteric sclerae (Salamina and D'Argenio, 1998).

The estimated average number of notified cases per year per 100,000 inhabitants is 11.7 in Campania and 53.3 in Puglia, which are in good agreement with the values reported in (ISTAT, 1980-2006), namely 14.3 in Campania and 52.6 in Puglia.

The model exhibits a "cluster-like pattern" (i.e., a large number of cases in a "short" period of time) within day care centers and kindergartens (see Figure 3d). As discussed before, this is a typical pattern of most childhood diseases (Galil et al., 2002), and hepatitis A as well (Chitambar et al., 1996).

\subsection{Effectiveness of vaccination programmes}

In presence of a vaccination programme of unlimited duration involving both newborns and 12-years-old adolescents, hepatitis A can be controlled quite well. By performing a very mild vaccination programme (vaccination coverage of $50 \%$ among 12-years-old adolescents and of $10 \%$ among newborns), the fraction of symptomatic individuals reduces of $26 \%$ in Campania and of $23 \%$ in Puglia in 50 years. In both regions, the cost of this vaccination campaign is about 570 vaccine doses per 100,000 individuals per year. Better results are obtained for higher vaccination coverage. In particular, for a very efficient vaccination strategy (vaccination coverage of 90\% among 12-years-old adolescents and of $80 \%$ among newborns), the fraction of symptomatic indi- 
Table 2

Effectiveness of vaccination and improvements in hygienic conditions in Campania*.

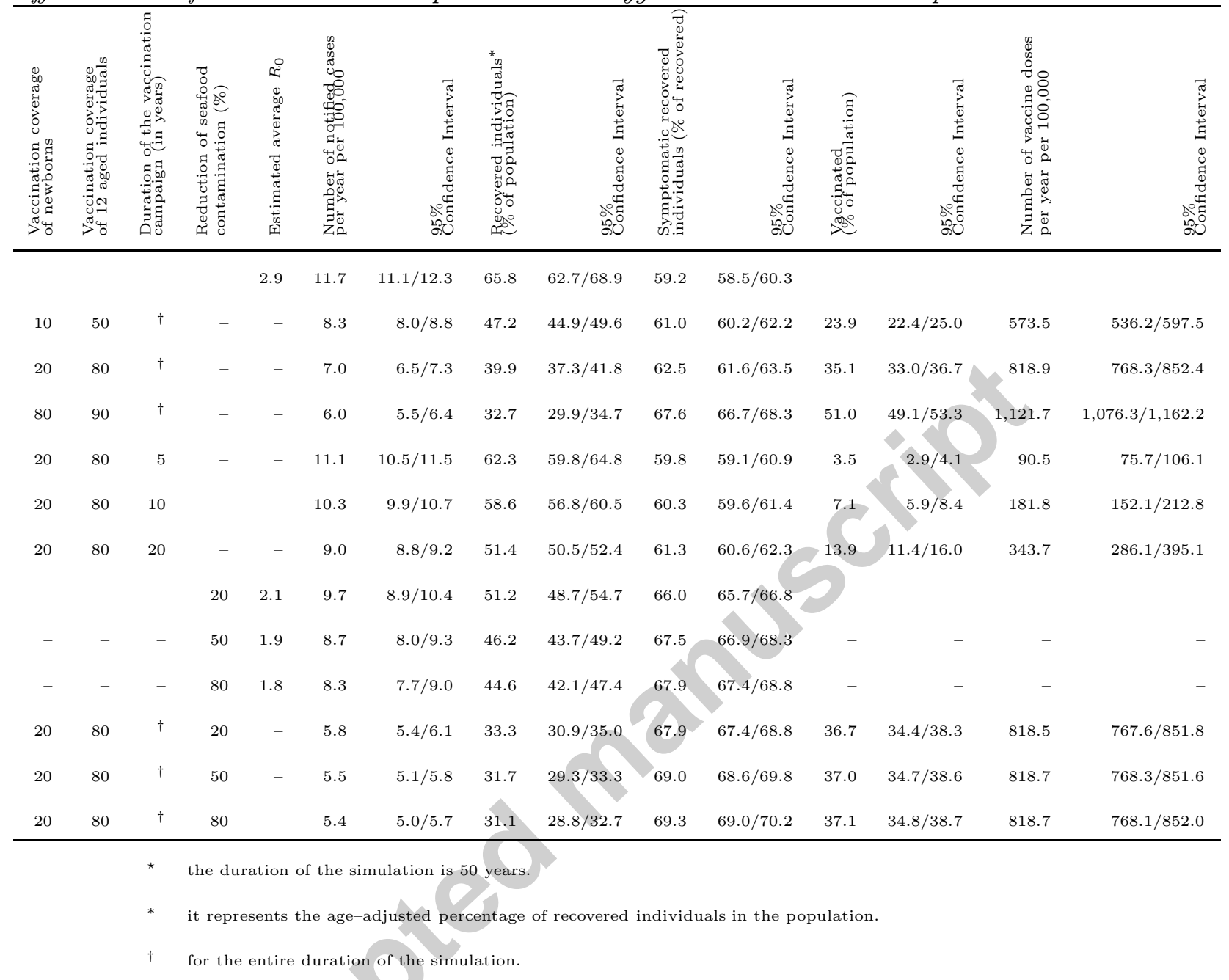

viduals declines to $22.1 \%$ in Campania and to $22.6 \%$ in Puglia, with a cost of about 1,100 vaccine doses per 100,000 individuals per year. Whatever vaccination programme is applied, hepatitis A can not be eliminated because some sporadic cases can be caused by travels to high endemicity areas.

A vaccination coverage of $20 \%$ among newborns and of $80 \%$ among $12-$ yearsold adolescents mimics the intervention implemented in Puglia which is the only Italian region that has introduced a vaccination programme started in 1997 (Lopalco et al., 2005), though vaccination is only recommended (and not mandatory): this is the reason of such a low vaccination coverage. In this 
Table 3

Effectiveness of vaccination and improvements in hygienic conditions in Puglia ${ }^{\star}$.

\begin{tabular}{|c|c|c|c|c|c|c|c|c|c|c|c|c|c|c|}
\hline 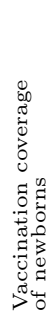 & 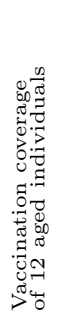 & 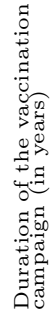 & 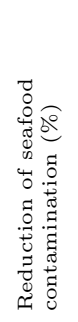 & 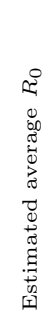 & 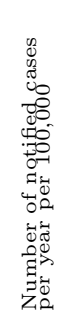 & 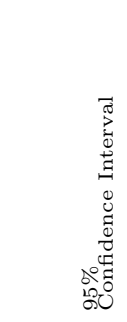 & 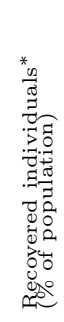 & 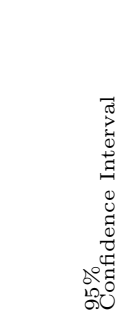 & 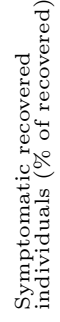 & 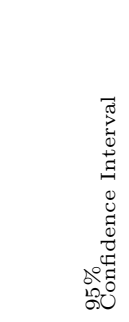 & 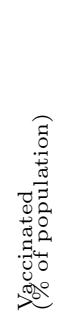 & 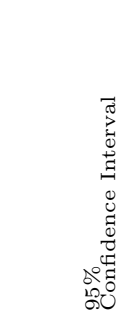 & 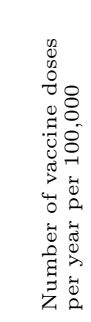 & 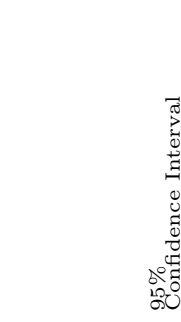 \\
\hline- & - & - & - & 3.8 & 53.3 & $50.9 / 54.0$ & 73.8 & $71.1 / 76.1$ & 51.9 & $50.9 / 53.9$ & - & - & - & - \\
\hline 10 & 50 & $\dagger$ & - & - & 37.6 & $35.8 / 39.6$ & 54.1 & $52.3 / 56.2$ & 54.3 & $53.3 / 56.3$ & 22.5 & $21.4 / 23.6$ & 573.4 & $536.0 / 597.5$ \\
\hline 20 & 80 & $\dagger$ & - & - & 30.6 & $29.2 / 32.5$ & 45.3 & $43.0 / 47.2$ & 56.1 & $55.2 / 58.0$ & 33.7 & $32.0 / 35.2$ & 818.7 & $768.2 / 852.1$ \\
\hline 20 & 80 & 5 & - & - & 50.6 & $48.4 / 52.6$ & 70.6 & $68.4 / 72.3$ & 52.6 & $51.5 / 54.4$ & 3.2 & & 90.5 & $75.8 / 105.8$ \\
\hline 20 & 80 & 10 & - & - & 47.9 & $46.0 / 49.4$ & 67.2 & $65.7 / 68.4$ & 53.2 & $52.3 / 54.9$ & 6.7 & $/ 7.7$ & 181.9 & $152.3 / 212.9$ \\
\hline 20 & 80 & 20 & - & - & 40.7 & $38.8 / 42.2$ & 57.0 & $56.1 / 58.0$ & 56.0 & $55.1 / 57.3$ & 13.4 & $11.0 / 15.3$ & 343.7 & $285.6 / 395.7$ \\
\hline- & - & - & 20 & 2.5 & 50.1 & $44.8 / 54.5$ & 60.3 & $57.1 / 64.0$ & 62.4 & $62.1 / 63.1$ & - & - & - & - \\
\hline- & - & - & 50 & 2.2 & 44.4 & $39.5 / 48.6$ & 53.5 & $51.0 / 57.1$ & 64.7 & $64.1 / 65.6$ & - & - & - & - \\
\hline- & - & - & 80 & 2.1 & 42.2 & $37.7 / 46.0$ & 51.1 & $48.5 / 54.4$ & & $64.7 / 66.4$ & - & - & - & - \\
\hline 20 & 80 & $\dagger$ & 20 & - & 26.6 & $24.8 / 28.6$ & 37.8 & $35.1 / 39.6$ & 64.4 & $64.0 / 65.2$ & 35.9 & $33.8 / 37.5$ & 818.6 & $767.8 / 852.0$ \\
\hline 20 & 80 & $\dagger$ & 50 & - & 24.7 & $23.0 / 26.5$ & 35.7 & $33.1 / 37.5$ & 66.1 & $65.7 / 67.0$ & 36.4 & $34.2 / 37.9$ & 818.7 & $768.3 / 851.8$ \\
\hline
\end{tabular}

setting, a vaccination campaign of limited duration (e.g., 10 years) does not have a significant effect in mitigating the epidemic. In fact, the fraction of recovered individuals decreases of only $5 \%$ in Campania and $4 \%$ in Puglia in 50 years. Figure 4a, 4d, 4g, 5a, 5d, 5g, Table 2 and 3 show how better results can be obtained by extending the vaccination campaign over a longer period.

In both the considered regions, when vaccination is performed for at least 20 years, the fraction of recovered individuals drastically decreases in almost all age classes (but for the class of $>59$ years old individuals) as an effect of the vaccination (see Figure $4 \mathrm{~b}, 4 \mathrm{e}, 4 \mathrm{~h}, 5 \mathrm{~b}, 5 \mathrm{e}$ and $5 \mathrm{~h}$ ). This reduction is not 
Table 4

Effectiveness of social distancing measures in Campania ${ }^{\star}$.

\begin{tabular}{|c|c|c|c|c|c|c|c|c|}
\hline 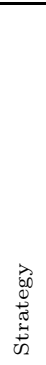 & 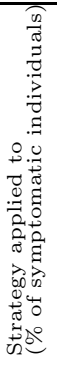 & 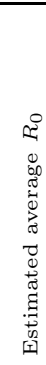 & 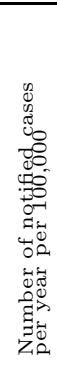 & 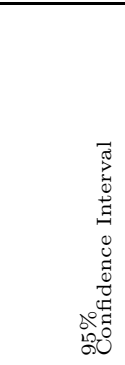 & 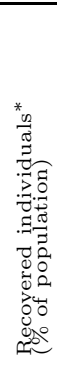 & 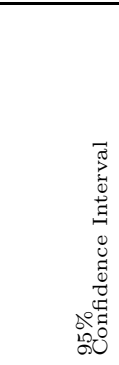 & 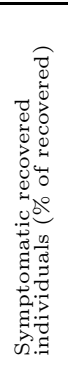 & 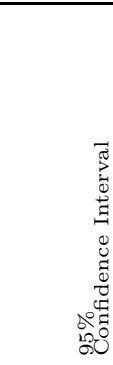 \\
\hline$d 1$ & 100 & 2.8 & 11.7 & $11.1 / 12.3$ & 64.3 & $61.0 / 67.5$ & 60.8 & $60.0 / 62.4$ \\
\hline$d 2$ & 100 & 2.8 & 11.7 & $11.1 / 12.3$ & 64.1 & $60.9 / 67.3$ & 61.0 & $60.2 / 62.6$ \\
\hline$d 3$ & 100 & 2.8 & 11.7 & $11.1 / 12.4$ & 64.1 & $60.9 / 67.3$ & 61.1 & $60.3 / 62.7$ \\
\hline$d 1$ & 50 & 2.9 & 11.7 & $11.2 / 12.3$ & 64.9 & $61.7 / 68.0$ & 60.2 & $59.4 / 61.6$ \\
\hline$d 2$ & 50 & 2.9 & 11.7 & $11.2 / 12.3$ & 64.7 & $61.6 / 67.9$ & 60.3 & $59.6 / 61.7$ \\
\hline$d 3$ & 50 & 2.9 & 11.8 & $11.2 / 12.3$ & 64.8 & $61.6 / 67.9$ & 60.4 & $59.7 / 61.8$ \\
\hline$d 1$ & 10 & 2.9 & 11.7 & $11.0 / 12.3$ & 65.6 & $62.4 / 68.7$ & 59.4 & $58.6 / 60.6$ \\
\hline$d 2$ & 10 & 2.9 & 11.7 & $11.1 / 12.3$ & 65.6 & $62.4 / 68.7$ & & $58.7 / 60.6$ \\
\hline$d 3$ & 10 & 2.9 & 11.7 & $11.1 / 12.3$ & 65.6 & $62.4 / 68.7$ & & $58.8 / 60.7$ \\
\hline$d 1$ & $\dagger$ & 2.9 & 11.7 & $11.1 / 12.3$ & 65.8 & $62.7 / 68.8$ & 59.2 & $58.5 / 60.3$ \\
\hline$d 2$ & $\dagger$ & 2.9 & 11.7 & $11.0 / 12.2$ & 65.8 & $62.7 / 68.8$ & 59.2 & $58.5 / 60.3$ \\
\hline$d 3$ & $\dagger$ & 2.9 & 11.7 & $11.1 / 12.2$ & 65.7 & $62.7 / 68.8$ & 59.2 & $58.5 / 60.4$ \\
\hline
\end{tabular}

* it represents the age-adjusted percentage of recovered individuals in the population.

* the duration of the simulation is 50 years.

$\dagger \quad$ strategy applied to only to notified cases.

observed in the class of elderly individuals since they lived most of their life before the start of the vaccination programme. When vaccination is performed for at least 20 years, age at infection increases with respect to the baseline simulations as a consequence of the higher protection in the younger (and vaccinated) individuals and of the overall reduction in the number of cases in the population (see Figure 4c, 4f, 4i, 5c, 5f and 5i). However, the increased age at infection is well compensated by the drastic reduction of the overall impact of the epidemic. 
Table 5

Effectiveness of social distancing measures in Puglia ${ }^{\star}$.

\begin{tabular}{|c|c|c|c|c|c|c|c|c|}
\hline 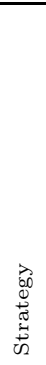 & 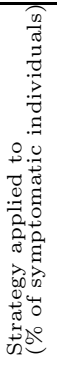 & 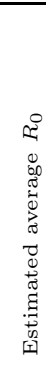 & 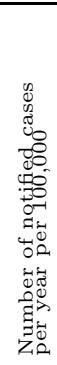 & 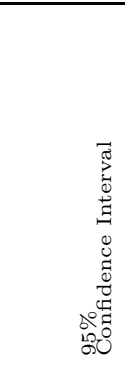 & 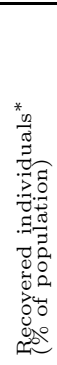 & 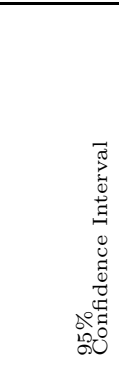 & 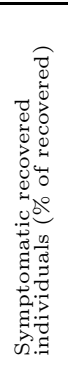 & 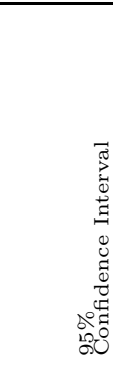 \\
\hline$d 1$ & 100 & 3.7 & 54.0 & $51.5 / 56.4$ & 72.8 & $69.9 / 75.2$ & 53.5 & $52.4 / 55.9$ \\
\hline$d 2$ & 100 & 3.7 & 54.2 & $51.6 / 56.8$ & 72.6 & $69.9 / 75.0$ & 53.7 & $52.6 / 56.1$ \\
\hline$d 3$ & 100 & 3.7 & 54.1 & $51.7 / 56.7$ & 72.6 & $69.8 / 75.0$ & 53.8 & $52.6 / 56.2$ \\
\hline$d 1$ & 50 & 3.8 & 53.7 & $51.1 / 56.0$ & 73.2 & $70.4 / 75.6$ & 52.9 & $51.8 / 55.1$ \\
\hline$d 2$ & 50 & 3.7 & 53.8 & $51.2 / 56.2$ & 73.1 & $70.3 / 75.5$ & 53.0 & $51.9 / 55.3$ \\
\hline$d 3$ & 50 & 3.7 & 53.8 & $51.3 / 56.1$ & 73.1 & $70.3 / 75.4$ & 53.1 & $52.0 / 55.3$ \\
\hline$d 1$ & 10 & 3.8 & 53.4 & $50.8 / 55.7$ & 73.6 & $70.9 / 76.0$ & 52.1 & $51.0 / 54.2$ \\
\hline$d 2$ & 10 & 3.8 & 53.3 & $50.9 / 55.4$ & 73.6 & $70.9 / 75.9$ & 52.1 & $51.1 / 54.2$ \\
\hline$d 3$ & 10 & 3.8 & 53.4 & $50.9 / 55.7$ & 73.6 & $70.8 / 75.9$ & 52.2 & $51.1 / 54.3$ \\
\hline$d 1$ & $\dagger$ & 3.8 & 53.3 & $50.8 / 55.5$ & 73.7 & $71.0 / 76.1$ & 52.0 & $50.9 / 54.1$ \\
\hline$d 2$ & $\dagger$ & 3.8 & 53.3 & $50.7 / 55.5$ & 73.7 & $71.0 / 76.0$ & 52.0 & $51.0 / 54.1$ \\
\hline$d 3$ & $\dagger$ & 3.8 & 53.3 & $50.8 / 55.5$ & 73.7 & $71.0 / 75.9$ & 52.0 & $50.9 / 54.1$ \\
\hline
\end{tabular}

* it represents the age-adjusted percentage of recovered individuals in the population.

* the duration of the simulation is 50 years.

$\dagger \quad$ strategy applied only to notified cases.

\subsection{Effectiveness of social distancing measures}

Social distancing measures $d 1, d 2$ and $d 3$ do not have any positive effect: neither the fraction of recovered individuals nor the number of notified cases, nor the $R_{0}$ decline (see Table 4 and 5). Specifically, only a slight decrease in the fraction of recovered individuals (of the order of $1-2 \%$, not statistically significant) can be observed when considering the more restrictive measures d2 and $d 3$ applied to the $100 \%$ of symptomatic individuals, which is fairly unrealistic. In the more realistic case of strategies applied only to notified 
cases, no significant differences are observable with respect to the baseline scenarios.

Moreover, an undesired observed effect is to decrease the fraction of children and adolescents who contract the infection while increasing that of adults and elderly people (see Figure 6). Since the probability of developing acute symptoms increases with age, these interventions can be considered counterproductive. This effect is more relevant in Puglia and it is due to the higher value of $R_{0}$ which results in a lower age at infection.

\subsection{Effects of improvements in hygienic conditions}

Improvements in hygienic conditions have a wide effect on the hepatitis A dynamics. Although the decrease in the number of notified cases is not so relevant (see Table 2 and 3), the fraction of recovered and symptomatic individuals noticeably declines in 50 years, leading to estimated values of $R_{0}$ of 1.8-2.1 in Campania and 2.1-2.5 in Puglia: this values are typical of mediumlow endemicity areas.

Finally, combining a vaccination programme with natural hygienic improvement leads, not surprisingly, to a very low fraction of recovered individuals values (see Table 2 and 3 ).

\section{Discussion}

The development of an algorithm for simulating the temporal evolution of the sociodemographic structure of the population, where individuals come 
to life, grow, attend school, go to work, can generate new households, can procreate and die, allowed us to develop the first large scale, spatially-explicit individual-based model, applied to the analysis of hepatitis A in Italy. The dynamic sociodemographic model proposed in this work can be easily adapted to the study of other endemic diseases in which person-to-person transmission can play a relevant role.

The model complies with the available epidemiological data (e.g., the seroprevalence or the fraction of cases generated in the different sources of infection) and it allows analyzing the effectiveness of different intervention measures. A low vaccination coverage of unlimited duration is able to reduce hepatitis $\mathrm{A}$, at a limited cost in terms of vaccine stockpile. However, a vaccination programme of limited duration does not result in a substantial decrease of the proportion of susceptible individuals in the population. Consequently, HAV can spread in the population and new outbreaks will arise as soon as the vaccination campaign is interrupted. Therefore, in the light of the results presented in this paper, the mass vaccination adopted in the region of Puglia in 1996-1997 can be effective only if the vaccination programme is protracted. Unfortunately, serological data for the pre-vaccination period and for the vaccination period in Puglia are not available to us. Therefore, it is hard to validate this result empirically.

Expected and desirable improvements in hygienic conditions are sufficient to lead to a decline of the epidemic, even in the absence of vaccination (as observed in (Jacobsen and Koopman, 2004, 2005)). The obtained estimates of $R_{0}$ suggest that the two high endemicity Italian regions could naturally evolve towards a medium-low endemicity level. The considered social distancing measures (isolation of symptomatic cases and closure of day care centers and 
kindergartens) do not have any positive effect on the containment of hepatitis A. On the contrary, the effect of these interventions is to decrease the fraction of children and adolescents who contract the infection while increasing that of adults and elderly people. Consequently, a side effect is to increase the risk of developing acute symptoms. In fact, blocking transmission in day care centers and kindergartens may not be an effective measure for decreasing the overall prevalence of infection in the population if more than $50 \%$ of cases are due to ingestion of infected seafood, as in the two considered regions (Mele et al., 2006). This kind of measures could be effective only when coupled to drastic improvements in hygienic conditions. Elimination of the disease is not possible since new cases are continuously imported from high endemicity areas outside the country.

The assumption of a constant population (neither immigration nor emigration are considered in the model and the number of newborns is assumed to be equal to the number of deaths) represents a critical issue, though this is a reasonable modeling choice. Since the demographic projections are not completely reliable, the longer the temporal interval of the simulations, the less accurate the predictions are expected to be. Individual-based models allow considering highly heterogeneous populations, improving the characterization of contacts and representing the age-structure in a natural way. They offer the advantage of avoiding (arbitrary) assumptions on the transmission rates among age classes. However, in order to estimate the transmission rates, they require specific data on (i) the type of contact and (ii) the frequency of contact in the different places where transmission can occur.

We focused the study on the two most affected Italian regions. Since the risk factors greatly vary from region to region (e.g., the consumption of raw 
seafood is not common in Northern Italy), it would be interesting to develop a nationwide model, to analyze, for instance, the mechanisms behind the spatiotemporal spread of the epidemic. In some more detail, it would be interesting to analyze the effects of a vaccination campaign conducted only in the most affected regions on the temporal evolution of viral hepatitis $\mathrm{A}$ in the rest of the country.

We conclude by remarking the main findings of this work, potentially related to the implementation of control measures by public health authorities. A low vaccination coverage is sufficient to reduce the impact of hepatitis $\mathrm{A}$, at a limited cost in terms of vaccine stockpile. However, if the vaccination programme is not protracted in time new outbreaks can arise as soon as the vaccination campaign is interrupted. Since vaccine is offered on a voluntary basis, it is thus crucial to carry out sensibilization measures. Improvements in hygienic conditions are sufficient to lead to a decline of the epidemic. Though they are difficult to achieve in a short period of time, monitoring of fish market stands and mass sensibilization campaigns could be implemented to raise consumer and industry awareness. Social distancing measures are discouraged from both clinical and social points of view. They could be reassessed in the light of high vaccination coverage and drastic improvements in hygienic conditions.

Acknowledgments We are grateful to Laura Fumanelli, Bruno Caprile and Giuseppe Jurman for reading earlier versions of the paper and providing useful suggestions. We are also grateful to two anonymous reviewers for their suggestions that certainly improved this manuscript. We thank the European Union FP7 FLUMODCONT and EPIWORK projects for research funding. 


\section{References}

Abad, F. X., Pinto, R. M., and Bosch, A. (1994). Survival of enteric viruses on environmental fomites. Applied and Environmental Microbiology, 60(10):3704-3710.

Ajelli, M., Iannelli, M., Manfredi, P., and Ciofi degli Atti, M. L. (2008). Basic mathematical models for the temporal dynamics of HAV in mediumendemicity Italian areas. Vaccine, 26(13):1697-1707.

Ajelli, M. and Merler, S. (2008). The Impact of the Unstructured Contacts Component in Influenza Pandemic Modeling. PLoS ONE, 3(1):e1519.

Anderson, R. M. and May, R. M. (1991). Infectious diseases of humans: dynamics and control. Oxford, UK: Oxford University Press.

Ansaldi, F., Bruzzone, B., Rota, M. C., Bella, A., Ciofi degli Atti, M. L., Durando, P., Gasparini, R., and Icradi, G. (2008). Hepatitis A incidence and hospital-based seroprevalence in Italy: a nation-wide study. European Journal of Epidemiology, 23:45-53.

Armstrong, G. L. and Bell, B. P. (2002). Hepatitis A virus infection in the Unites States: model-based estimates and implications for childhood immunization. Pediatrics, 109:839-845.

Averhoff, F., Shapiro, C. N., Bell, B. P., Hyams, I., Burd, L., Deladisma, A., Simard, E. P., Nalin, D., Kuter, B., Ward, C., Lundberg, M., Smith, N., and Margolis, H. S. (2001). Control of Hepatitis A Through Routine Vaccination of Children. Journal of the American Medical Association, 286(23):29682973.

Berge, J. J., Drennan, D. P., Jacobs, R. J., Jakins, A., Meyerhoff, A. S., Stubblefield, W., and Weinberg, M. (2000). The cost of hepatitis A infections in American adolescents and adults in 1997. Hepatology, 31(2):469-473. 
Biziagos, E., Passagot, J., Crance, J. M., and R., D. (1988). Long-term survival of Hepatitis A virus and poliovirus Type 1 in mineral water. Applied and Environmental Microbiology, 54(11):2705-2710.

CDC (2006). Disease Burden from Hepatitis A, B, and C in the United States. http://www.cdc.gov/ncidod/diseases/hepatitis/ resource/dz_burden.htm. Centers for Disease Control and Prevention.

CDC (2007). Health Information for International Travel 2008. Atlanta, US, Department of Health and Human Services, Public Health Service. Centers for Disease Control and Prevention.

Chironna, M., Germinario, C., De Medici, D., Fiore, A., Di Pasquale, S., Quarto, M., and Barbuti, S. (2002). Detection of hepatitis A virus in mussels from different sources marketed in Puglia region (South Italy). International Journal of Food Microbiology, 75:11-18.

Chironna, M., Grottola, A., Lanave, C., Villa, E., Barbuti, S., and Quarto, M. (2003). Genetic analysis of HAV strains recovered from patients with acute hepatitis from Southern Italy. Journal of Medical Virology, 70(3):343-349.

Chitambar, S. D., Chadha, M. S., Yeolekar, L. R., and Arankalle, V. A. (1996). Hepatitis A in day care centre. Indian Journal of Pediatrics, 63(6):781-783. Chowell, G., Hengartner, N. W., Castillo-Chavez, C., Fenimore, P. W., and Hyman, J. M. (2004). The Reproductive Number of Ebola and the Effects of Public Health Measures: The cases of Congo and Uganda. Journal of Theoretical Biology, 229(1):119-126.

Ciofi degli Atti, M. L., Merler, S., Rizzo, C., Ajelli, M., Massari, M., Manfredi, P., Furlanello, C., Scalia Tomba, G., and Iannelli, M. (2008). Mitigation measures for pandemic influenza in Italy: an individual based model considering different scenarios. PLoS ONE, 3(3):e1790.

D’Amelio, R., Mele, A., Mariano, A., Roman, L., Biselli, R., Lista, F., Zanetti, 
A., and Stroffolini, T. (2005). Hepatitis A, Italy. Infectious Diseases, 11(7). Das, A. (2003). An economic analysis of different strategies of immunization against hepatitis A virus in developed countries. Hepatology, 29(2):548-552. Eubank, S., Guclu, H., Kumar, A. V. S., Marathe, M. V., Srinivasan, A., Toroczkai, Z., and Wang, N. (2004). Modelling disease outbreaks in realistic urban social networks. Nature, 429:180-184.

Ferguson, N. M., Cummings, D. A., Cauchemez, S., Fraser, C., Riley, S., Meeyai, A., Iamsirithaworn, S., and Burke, D. S. (2005). Strategies for containing an emerging influenza pandemic in Southeast Asia. Nature, 437:209214.

Ferguson, N. M., Cummings, D. A., Fraser, C., Cajka, J. C., Cooley, P. C., and Burke, D. S. (2006). Strategies for mitigating an influenza pandemic. Nature, 442:448-452.

Fiore, A. E. (2004). Hepatitis A Transmitted by Food. Clinical Infectious Diseases, 38:705-715.

Galil, K., Lee, B., Strine, T., Carraher, C., Baughman, A. A., Eaton, M., Montero, J., and Seward, J. (2002). Outbreak of Varicella at a Day-Care Center despite Vaccination. The New England Journal of Medicine, 347(24):19091915.

Germann, T. C., Kadau, K., Longini, I. M. J., and Macken, C. A. (2006). Mitigation strategies for pandemic influenza in the United States. Proceedings of the National Academy of Sciences, 103(15):5935-4.

Halloran, M. E., Longini, I. M. J., Nizam, A., and Yang, Y. (2002). Containing Bioterrorist Smallpox. Science, 298:1428-1432.

Iannelli, M. and Manfredi, P. (2007). Demographic Change and Immigration in Age-structured Epidemic Models. Mathematical Population Studies, 14(3):169-191. 
ISTAT (1974-2004). Life tables. http://demo.istat.it/unitav/index. html?lingua=eng. Italian Institute of Statistics.

ISTAT (1980-2006). Annuario statistico Italiano. Italian Institute of Statistics.

ISTAT (2001a). VIII Censimento generale dell'industria e dei servizi. http: //dwcis.istat.it/cis/index.htm. Italian Institute of Statistics.

ISTAT (2001b). XIV Censimento generale della popolazione e delle abitazioni. http://dawinci.istat.it/MD/. Italian Institute of Statistics.

ISTAT (2003). Strutture familiari e opinioni su famiglia e figli. http://www. istat.it/dati/catalogo/20060621_03/. Italian Institute of Statistics.

ISTAT (2007). Resident population. http://demo.istat.it/pop2007/ index_e.html. Italian Institute of Statistics.

ISTAT (2008). Matrimoni, separazioni e divorzi. http://www.istat.it/ altridati/matrimoni/. Italian Institute of Statistics.

Jacobsen, K. H. and Koopman, J. S. (2004). Declining hepatitis A seroprevalence: a global review and analysis. Epidemiology and Infection, 132:10051022.

Jacobsen, K. H. and Koopman, J. S. (2005). The effects of socioeconomic development on worldwide hepatitis A virus seroprevalence patterns. International Journal of Epidemiology, 34:600-609.

Lerman, Y., Chodik, G., Aloni, H., Ribak, J., and Ashkenazi, S. (1999). Occupations at Increased Risk of Hepatitis A: A 2-Year Nationwide Historical Prospective Study. American Journal of Epidemiology, 150(3):312-320.

Longini, I. M. J., Halloran, M. E., Nizam, A., and Yang, Y. (2004). Containing Pandemic Influenza with Antiviral Agents. American Journal of Epidemiology, 159:623-633.

Longini, I. M. J., Halloran, M. E., Nizam, A., Yang, Y., Xu, S., Burke, D., 
Cummings, D., and Epstein, J. (2006). Containing a Large Bioterrorist Smallpox Attack: A Computer Simulation. International Journal of Infectious Diseases, 11:98-108.

Longini, I. M. J., Nizam, A., Xu, S., Ungchusak, K., Hanshaoworakul, W., Cummings, D. A., and Halloran, M. E. (2005). Containing pandemic influenza at the source. Science, 309(5737):1083-7.

Lopalco, P. L., Malfait, P., Menniti-Ippolito, F., Prato, R., Germinario, C., Chironna, M., Quarto, M., and Salmaso, S. (2005). Determinants of acquiring hepatitis A virus disease in a large Italian region in endemic and epidemic periods. Journal of Viral Hepatitis, 12(3):315-321.

Lopalco, P. L., Malfait, P., Salmaso, S., Germinario, C., Salamina, G., Quarto, M., Barbuti, S., Cipriani, R., Mundo, A., and Pesole, G. (1997). A persisting outbreak of hepatitis A in Puglia, Italy, 1996: epidemiological follow-up. Euro Surveillance, 2(4):31-32.

Lucioni, C., Cipriani, V., Mazzi, S., and M., P. (1998). Cost of an Outbreak of Hepatitis A in Puglia, Italy. Pharmaco Economics, 13(2):257-266.

Mbithi, J. N., Springthorpe, V. S., and Sattar, S. A. (1991). Effect of relative humidity and air temperature on survival of Hepatitis A virus on environmental surfaces. Applied and Environmental Microbiology, 57(5):1394-1399.

Mele, A., Tosti, M., Spada, E., Mariano, A., Bianco, E., and Group, S. C. (2006). Epidemiology of acute viral hepatitis: twenty years of surveillance through SEIEVA in Italy and a review of the literature. Technical Report ISTISAN, 12(6):1-39.

MIUR (2005a). La scuola in cifre. http://www.miur.it/ustat/documenti/ pub2005/. Italian Ministry of University and Research.

MIUR (2005b). L'università in cifre. http://www.miur.it/ustat/ documenti/pub2005/. Italian Ministry of University and Research. 
Murray, C. J. L. and Lopez, A. D. (1997). Mortality by cause for eight regions of the world: Global Burden of Disease Study. The Lancet, 349:1269-1276.

Riley, S. (2007). Large-Scale Spatial-Transmission Models of Infectious Disease. Science, 316:1298-1301.

Riley, S. and Ferguson, N. M. (2006). Smallpox transmission and control: Spatial dynamics in Great Britain. Proceedings of the National Academy of Sciences, 103(33):12637-12642.

Salamina, G. and D'Argenio, P. (1998). Shellfish consumption and awareness of risk of acquiring hepatitis A among Neapolitan families - Italy 1997. Euro Surveillance, 3(10).

Shuval, H. (2003). Estimating the global burden of thalassogenic diseases: human infectious diseases caused by wastewater pollution of the marine environment. Journal of Water and Health, 1:53-64.

Stapleton, J. T. and Lemon, S. M. (1994). Infectious Diseases, chapter Hepatitis A and hepatitis E, pages 790-797. Philadelphia, US, Lippincott Co. Viboud, C., Bjornstad, O., Smith, D., Simonsen, L., Miller, M., and Grenfell, B. (2006). Synchrony, Waves, and Spatial Hierarchies in the Spread of Influenza. Science, 312(5772):447-451. 
Fig. 1. a Age structure (year 2007) of Campania region (black line) and age structure simulated by the sociodemographic model (gray line). c Italian household size (black bars) and household size simulated by the model in Campania (gray bars). Note that data on household size are not directly employed in the algorithm (see Supplementary Materials). $\mathbf{b}$ and $\mathbf{d}$ as $\mathbf{a}$ and $\mathbf{c}$, but for Puglia.

Fig. 2. a Age structure of Campania (black line) and age structures simulated by the sociodemographic model: projections to the years 2012, 2017 and 2022 (from dark gray to light gray). c As a but for frequencies of household size. e As a but for frequencies of employment categories. $\mathbf{b}, \mathbf{d}, \mathbf{f}$ as $\mathbf{a}, \mathbf{c}, \mathbf{e}$ but for Puglia region.

Fig. 3. a Risk factors by age group. Comparison between the National data reported in (Mele et al., 2006) (black bars) and the baseline simulations in Campania (dark gray bars) and Puglia (light gray bars). Children account for individuals aged 0-14, Young for individuals aged 15-24 and Adults for individuals older than 24 years old. b HAV seroprevalence by age cohort. Comparison between National data as reported in (Ansaldi et al., 2008) (black bars) and baseline simulations in Campania (dark gray bars) and Puglia (light gray bars). c Age at infection of symptomatic individuals in Campania (black bars) and Puglia (gray bars). d Number of cases over time in three randomly chosen day care centers in Puglia $\left(R_{0}=3.8\right)$, highlighting the classical "clusters-like pattern". The numbers refer to the fraction of cases over the number of children enrolled. 
Fig. 4. Effects of a vaccination programme in Campania. Vaccination coverage is assumed to be $20 \%$ among newborns and $80 \%$ among 12 years old adolescents. a percentage of susceptible individuals over time (light gray area), recovered individuals (dark gray area), vaccinated individuals (black area) and infected individuals ("small" white area between susceptible and recovered individuals) for a vaccination programme lasting 5 years. b HAV seroprevalence by age cohort for a vaccination programme lasting 5 years. c Age at infection of symptomatic individuals (black bars) and asymptomatic individuals (gray bars) for a vaccination programme lasting 5 years. d, e, f as a, b, c, but for a vaccination programme lasting 20 years. $\mathbf{g}$, $\mathbf{h}, \mathbf{i}$ as $\mathbf{a}, \mathbf{b}$, c, but for a vaccination programme lasting 50 years.

Fig. 5. Effects of a vaccination programme in Puglia. Vaccination coverage is assumed to be $20 \%$ among newborns and $80 \%$ among 12 years old adolescents. a percentage of susceptible individuals over time (light gray area), recovered individuals (dark gray area), vaccinated individuals (black area) and infected individuals ("small" white area between susceptible and recovered individuals) for a vaccination programme lasting 5 years. b HAV seroprevalence by age cohort for a vaccination programme lasting 5 years. c Age at infection of symptomatic individuals (black bars) and asymptomatic individuals (gray bars) for a vaccination programme lasting 5 years. d, e, f as a, b, c, but for a vaccination programme lasting 20 years. $\mathbf{g}$, $\mathbf{h}, \mathbf{i}$ as $\mathbf{a}, \mathbf{b}, \mathbf{c}$, but for a vaccination programme lasting 50 years.

Fig. 6. a Social distancing measure $d 3$ applied to all symptomatic individuals: variation of the number of cases (gray bars) and number of symptomatic cases (black bars) in Campania by age cohorts. b As a but for Puglia region. 
a

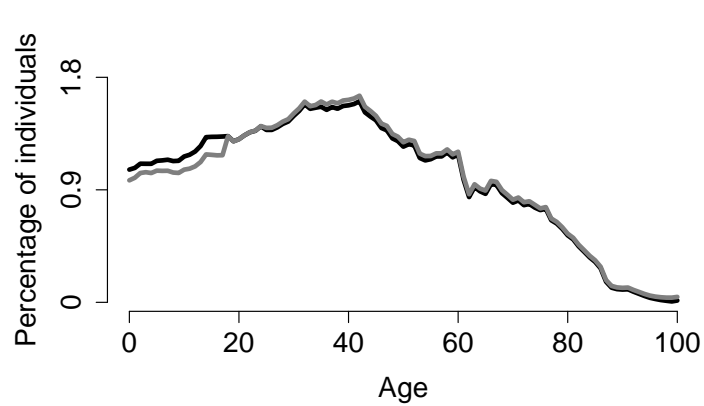

c

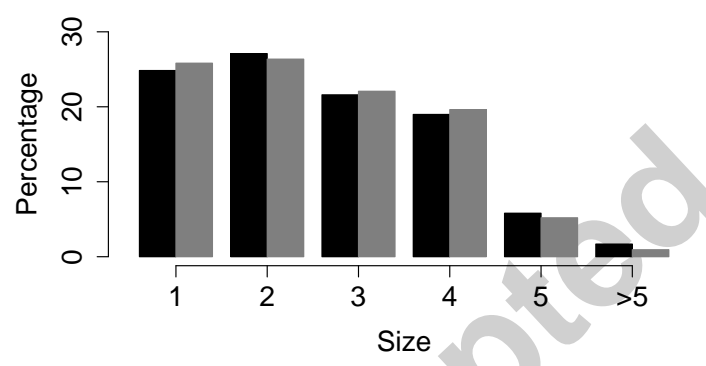

b

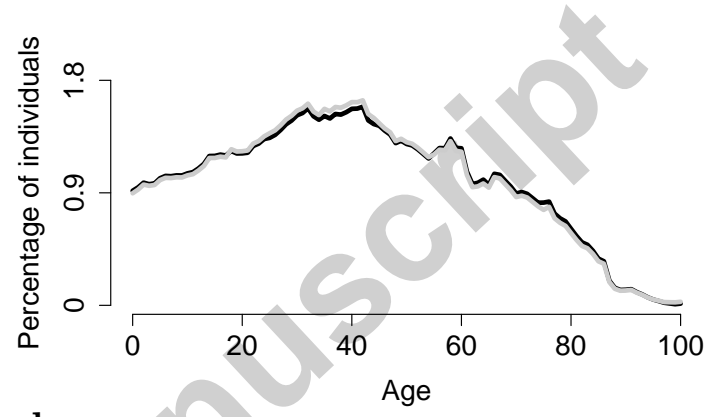

d

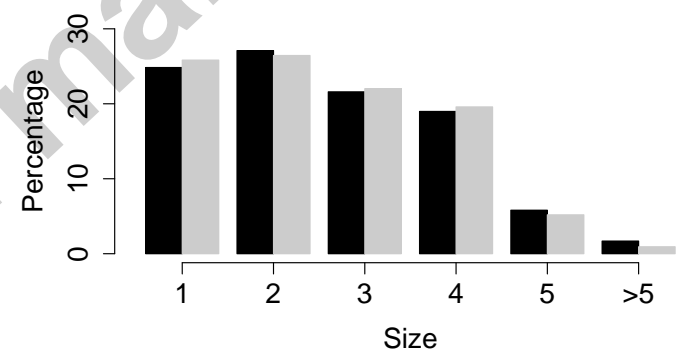


a

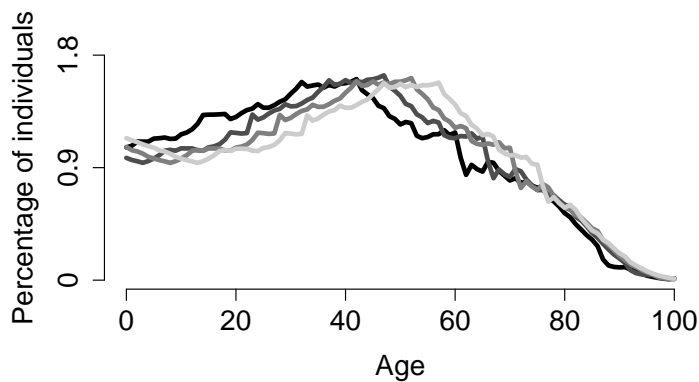

C

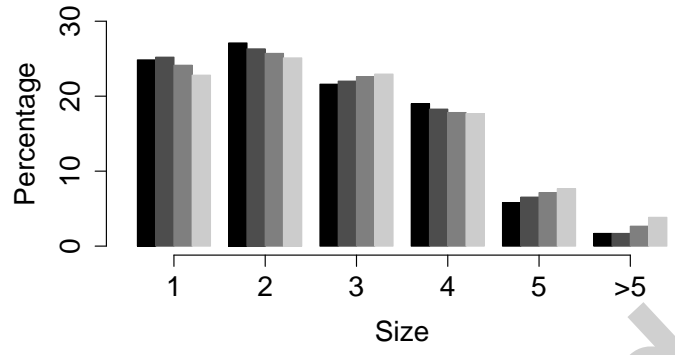

e

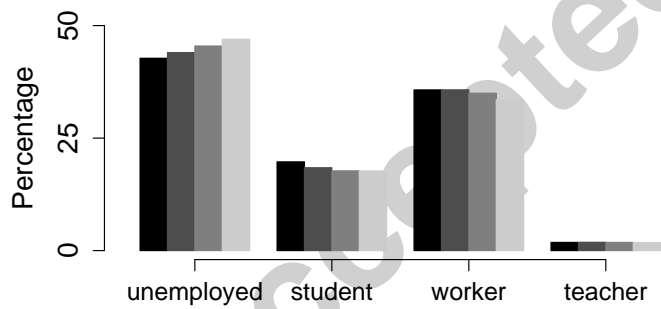

b

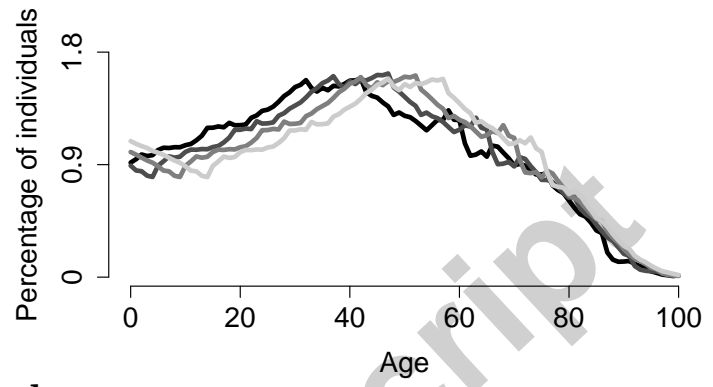

d

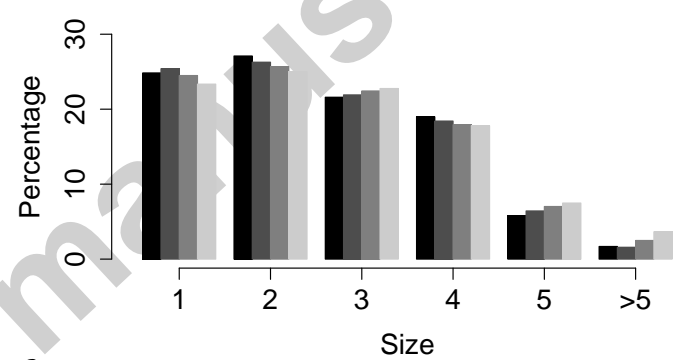

f

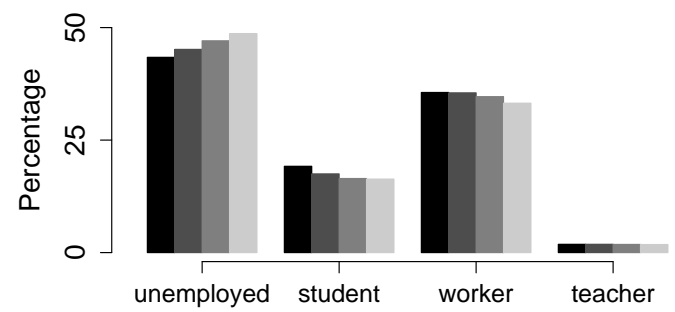


a
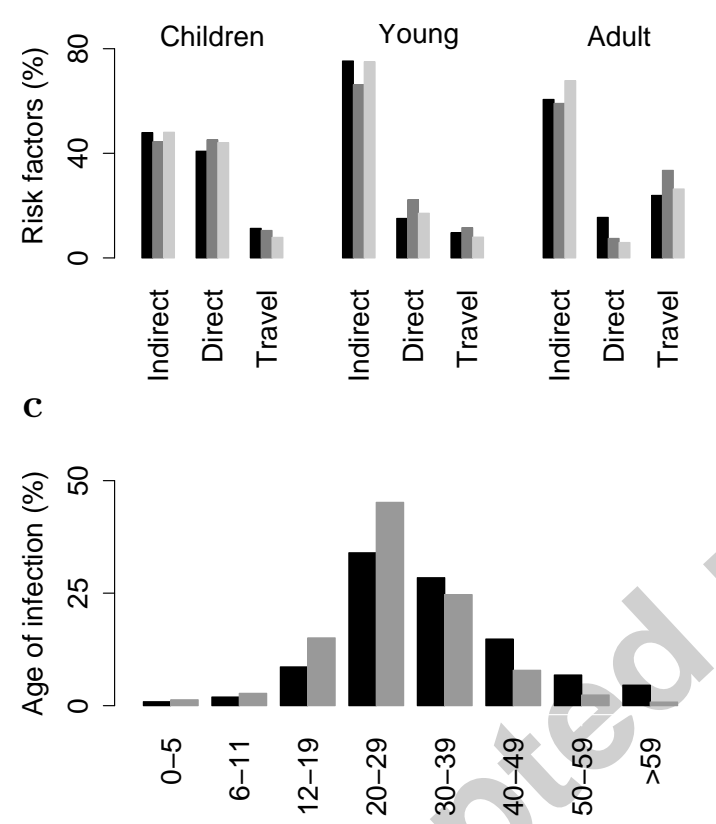

b
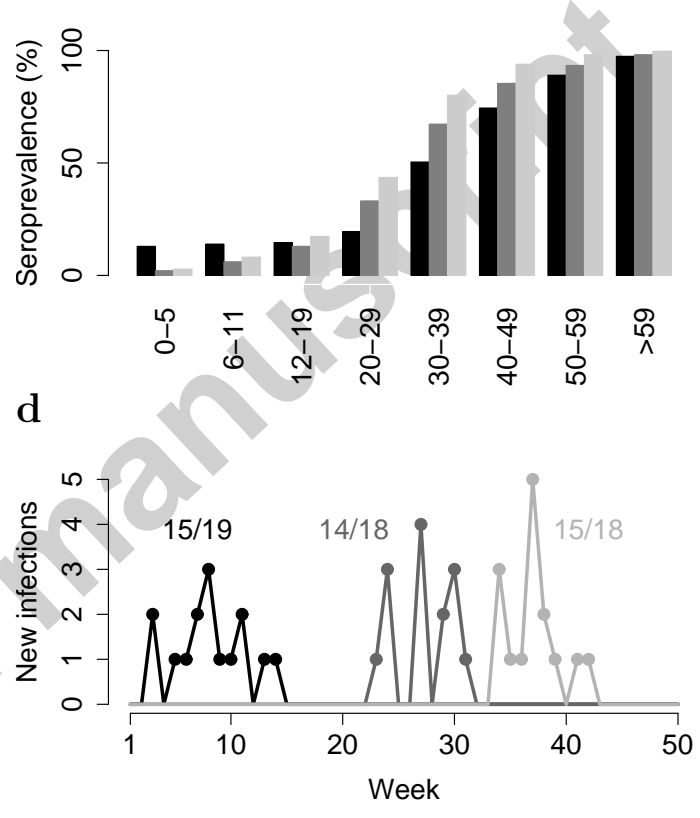
a

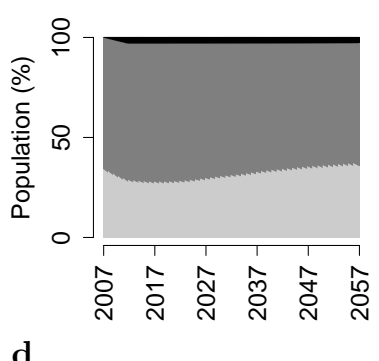

d

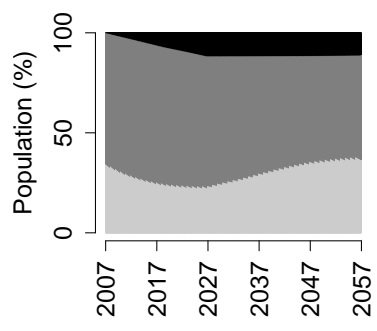

g

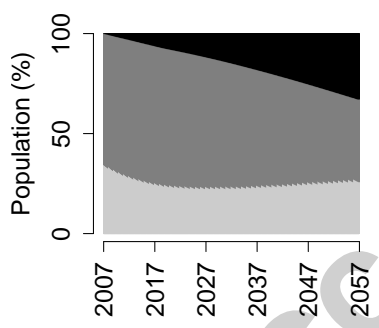

b

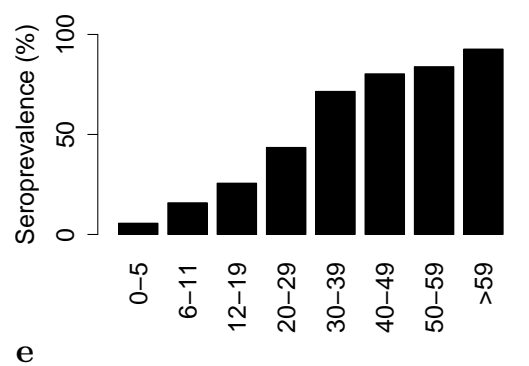

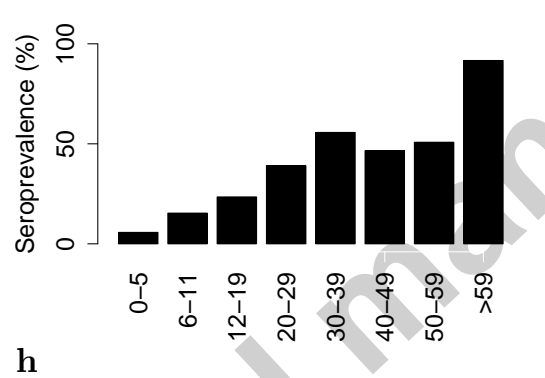

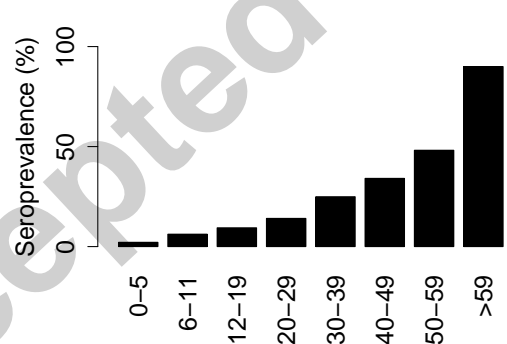

c

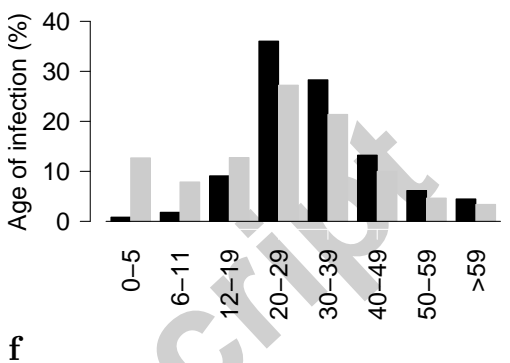

f
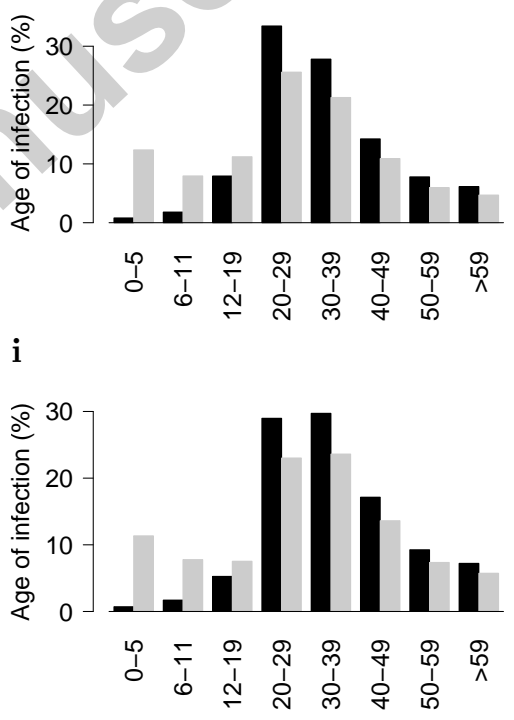
a

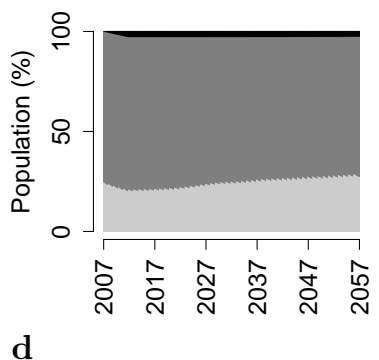

d

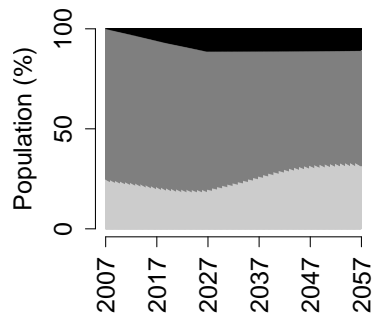

g

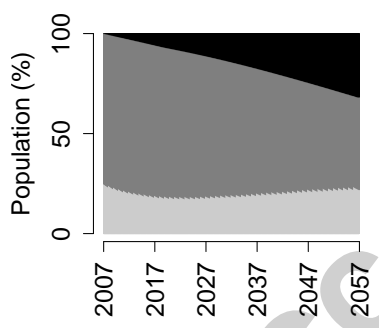

b
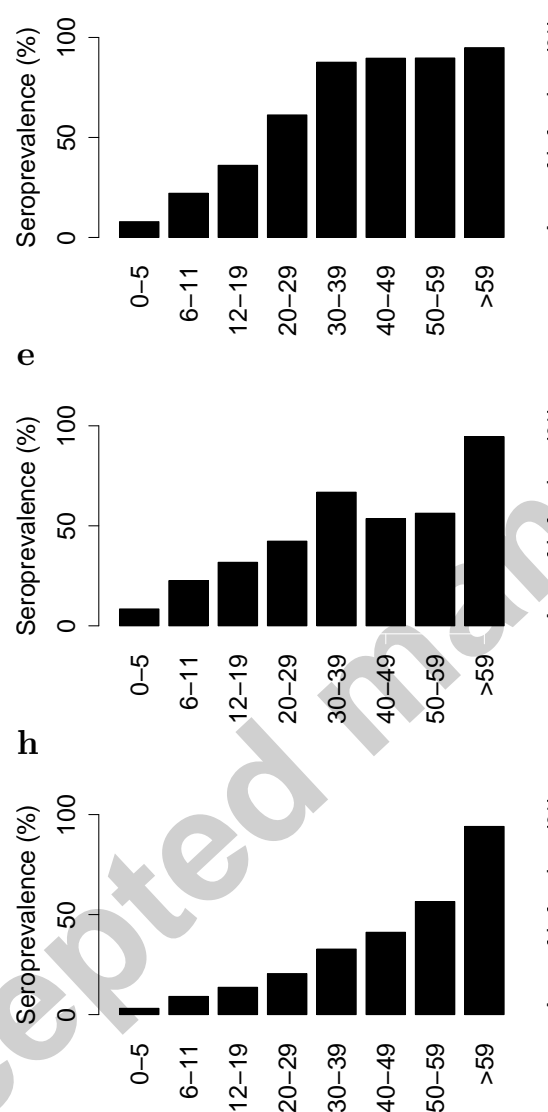

c
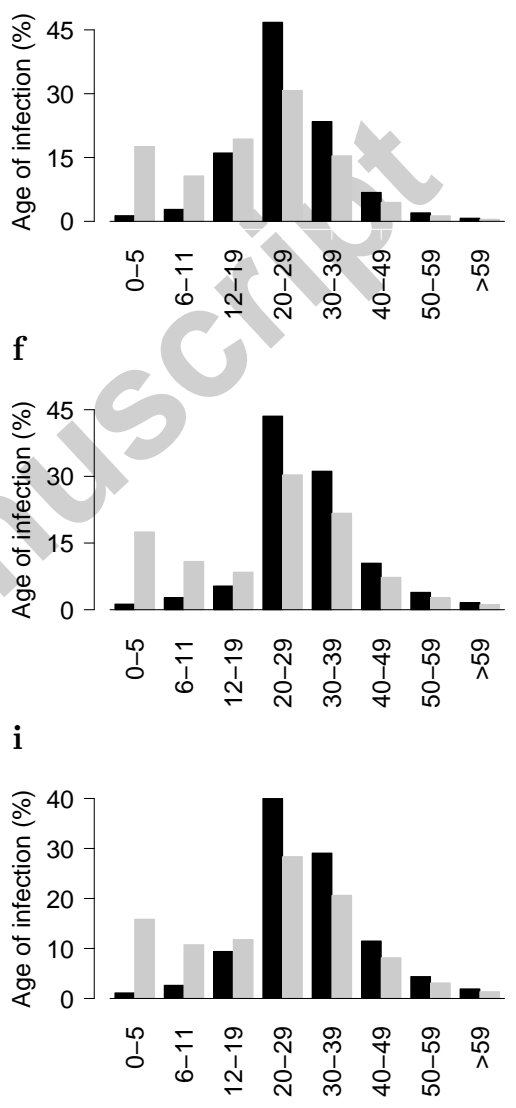
a

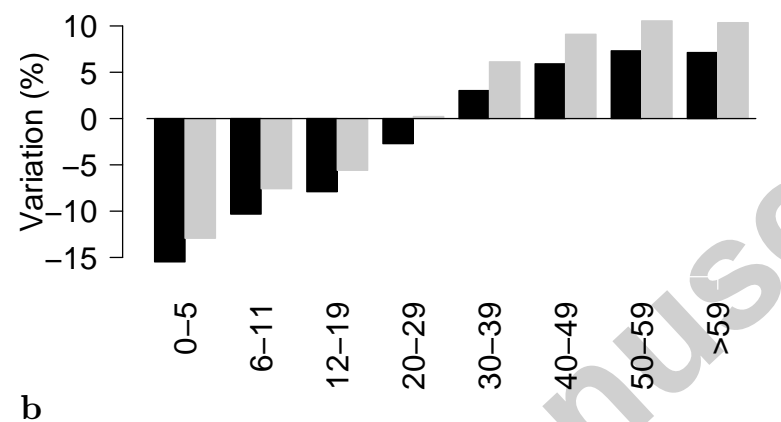

b

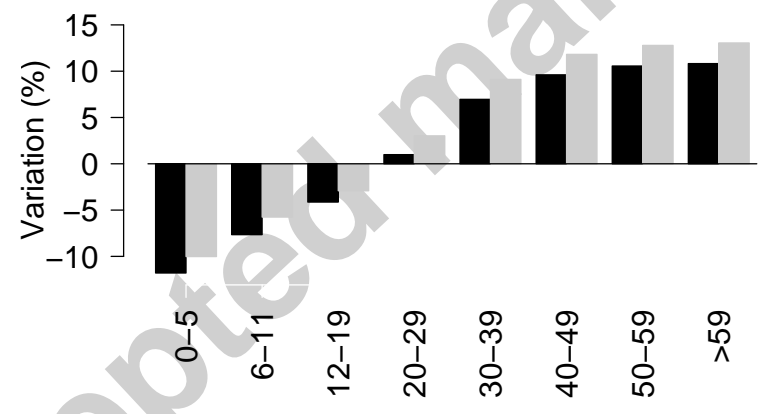

